\title{
Editorial
}

\section{Do we know the value of what we are doing?}

\begin{abstract}
The demand for evaluation of science communication practices and the number and variety of such evaluations are all growing. But it is not clear what evaluation tells us - or even what it can tell us about the overall impacts of the now-global spread of science communication initiatives. On the other hand, well-designed evaluation of particular activities can support innovative and improved practices.
\end{abstract}

As science communication becomes institutionalised in more and more countries around the world, and public engagement initiatives spread, most of us in the science communication communities of practice, education and research feel encouraged and validated. In this developmental phase of science communication, increments of whatever character tend to be welcomed.

The global expansion is accompanied by books and courses that offer prescriptions for 'effective' or 'successful' science communication. But what are the criteria by which success is measured? What are the effects being achieved that makes science communication 'effective'? After three decades of expansion, we are obliged to ask ourselves: how do we know the value of all this activity?

The regular outbursts of anxiety around publication of the PISA ${ }^{1}$ results, or the declining interest in science careers, or the levels of public interest in scientific developments, have changed little over the years, suggesting that the resources devoted to affecting these trends may have been wasted, at least in part.

Many countries regard it as essential to have at least one major science centre and a government programme on science awareness, but the impacts of having these in place or even of not having them in place, are not known with any certainty. More than that, they may not be knowable with any certainty.

Those engaged in science communication initiatives have some sense that they are doing the right thing and, intuitively at least, that they are doing it in the right way. But funding agencies and institutions want stronger assurance that the resources devoted to such practices are well used.

The external pressures are increasing on science communication practice to give an account of itself. The absence of formal evaluation is taken as a sign of weakness or under-development. The Wellcome Trust's review of two commissioned reports on informal learning includes a strong statement on the need for rigorous evaluation of informal

\footnotetext{
${ }^{1}$ Programme for International Student Assessment.
} 
learning programmes and for developing the connections between research and practice in the field [1].

The review considers that "informal science learning practitioners can be characterised more as craftspeople operating through a model of apprenticeship, observation and audience approval"; it contrasts this with a professional approach "whereby formalised mechanisms are developed to ensure knowledge is recorded and training is made available".

Another major funder, the European Commission, has also shown interest in the development of procedures for evaluating science in society activities. Several current and recent EC-funded projects in this field have evaluation activity or development of evaluation methods written into them. Gema Revuelta writes in this edition about the EC-funded PLACES $^{2}$ project's impact assessment toolkit. The EC-funded PERARES ${ }^{3}$ project, in which the present writer participated, also developed templates for evaluating public engagement projects at several stages.

It is not only external or funders' pressure that is driving this activity. Providing information to stakeholders is only one reason among several to do evaluation. Science centres and museums have been to the fore in designing and implementing visitor surveys and other evaluation procedures, intended to inform and improve their own practice. Carmen Sanchez summarises in this edition the trend over several decades in the direction of such evaluation. Evaluation is a popular topic in presentations and discussions at conference of science-centre professionals, science event organisers and other science communicators.

But matching the increasingly prevalent discourse about evaluation, there is - inevitably - a counter-discourse about the burden of form-filling and accounting activity, and the fear that only practices 'proven' to be effective will be supported. There are also indications of a kind of inert resistance to the demands of evaluation, perhaps reflecting a reluctance to change established practices.

The typical feedback forms that are widely used at science events - like other types of event - tend to be used to confirm established practices, on the basis that most participants were satisfied. But such feedback may be little more revealing than a 'like' on a Facebook page. Among the many questions evaluation of that kind leaves untouched is: what did people miss who did not attend the event?

Approached in a different spirit, evaluation can be an important support for innovation and improvement in science communication. Early-stage and mid-point assessments (formative evaluation as discussed by Giuseppe Pellegrini in this edition), can in its various forms identify problems at a stage when they still be addressed, and can support good (and better) practice.

The authors of the PERARES evaluation templates - who included this writer advised their users, "filling in the forms does not constitute the evaluation. It is the analysis of the responses and reflection on this analysis that makes for an evaluation. It is the responsibility of the key partners to ensure all other partners have an opportunity to respond to the evaluation findings".

\footnotetext{
${ }^{2}$ Platform of Local Authorities and Communicators Engaged in Science.

${ }^{3}$ Public Engagement with Research and Research Engagement with Science.
} 
Evaluation can be a means to make science communication internally dialogical, a means to support continuous quality improvement, an agency for reflexivity. Many science communication institutions think of themselves as learning organisations as well as organisations that support other people's learning; evaluation is a means for such selflearning to happen.

There is also learning to be had across the broader science communication communities. Even allowing for cultural differences, there are lessons to be learned from applying certain methods of practice in one place that might guide practitioners in another context not to repeat those methods, or to change them significantly.

In view of the 'global spread of science communication' [2], evaluation, and specifically the sharing of its results, can be a means to avoid re-invention of the wheel. An Australian study noted over a decade ago that evaluations in the 1990s did not establish if that country's science awareness programme "caused Australians to become more or less aware of science and technology or of the part science plays in stimulating social and economic development" [3]; the authors recommend that evaluation needed to be built into such programmes from the start.

Designing such evaluation would be very challenging. There are many difficult issues in evaluation methodology but also in establishing the conceptual basis of evaluation, as explored in this edition by Eric Jensen and Andrea Bandelli. When it comes to assessing the longer-term impacts of particular initiatives or institutions, the difficulties multiply. But if great difficulty and complexity were reasons for not making the effort, how much science, or science communication, would there be?

\section{Brian Trench}

\section{References}

[1] C. Matterson and J. Holman (2012), Informal science learning review: reflections from the Wellcome Trust: science beyond the classroom series, Wellcome Trust, London, U.K., online at http://www.wellcome.ac.uk/stellent/groups/corporatesite/@msh_peda/documents/web_document/ wtp040859.pdf, accessed 4 February 2014.

[2] B. Trench et al. (2014), "Global spread of science communication: institutions and practices across continents", in M. Bucchi and B. Trench eds., Handbook of Public Communication of Science and Technology, $2^{\text {nd }}$ edition, Routledge, U.K. (forthcoming).

[3] T. Gascoigne and J. Metcalfe (2001), "The evaluation of national programs of science awareness", Sci. Commun. 23: 66-76.

\section{Author}

Brian Trench is a researcher, evaluator and trainer in science communication, formerly senior lecturer in the School of Communications, Dublin City University, Ireland, and co-ordinator there of the Masters in Science Communication. He is co-editor with Massimiano Bucchi of Handbook of Public Communication of Science and Technology, $2^{\text {nd }}$ edition, to be published in 2014 by Routledge. E-mail: brian.trench@dcu.ie.

How to CITE: B. Trench, Do we know the value of what we are doing?, JCOM 13(01)(2014)E. 